\title{
O lugar de objeto e a materialização linguística dos sentidos em fuga
}

\section{The place of object and the linguistic materialization of the fleeing senses}

Doutora em linguística pela Faculdade de Letras da Universidade Federal de Minas Gerais (2013). São João del-Rei e membro do grupo de pesquisa ENUNCIAR, da Universidade Federal de Minas Gerais. Suas principais áreas de estudo são: semântica, sintaxe, enunciação. (i) http://orcid.org//000-0002-3652-7299 mail: lucianid@ufsj.edu.br

2 Mestranda do Programa de Pós-Graduação em de São João del-Rei na área de Discurso e Representacão Social, cuja ênfase se dá em Semântica da Enunciação. É integrante do grupo de pesquisa ENUNCIAR, da Universidade Federal de Minas Gerais. 0000-0002-8530-2897 E-mail: v-stussi@hotmail.com

Recebido em: 13/10/2018 Aprovado em: 1/3/2019.

Endereço para correspondência: Universidade Federal de São João del-Rei Praça Frei Orlando, 170 - Centro

\section{RESUMO}

Discutimos neste texto a produtividade do objeto verbal sob a ótica da relação entre as configurações orgânicas da língua e suas projeções de acionamento enunciativo. Defendemos que esse lugar sintático é constituído não apenas por um espaço na arquitetura da sentença, mas também por aspectos enunciativos que se mobilizam para configurá-lo como um lugar capaz de oferecer progressão referencial ao acontecimento posto em cena pelo dizer. De maneira específica, a análise da projeção do lugar de objeto realizada pelo verbo, não obrigatoriamente explícito, demonstra que esse lugar é profícuo para aquilo que Orlandi (2012) nomeia de fuga dos sentidos. Verificamos que a ausência de um objeto explícito não prescinde de uma ocupação virtual por formações nominais que materializem regularidades historicamente delineadas e propomos o conceito de "intercâmbio entre formações nominais", assumindo que o fluxo dos sentidos pode também ser estimulado pela ocupação de duas (ou mais) formações nominais diferentes no mesmo lugar de objeto.

Palavras-chave: Semântica da enunciação. Sentidos em fuga. Objeto verbal.

\section{ABSTRACT}

It is debated in this paper the productivity of verbal object under the perception of the relation between the organic language configurations and their projections of enunciative activation. Our point of view stresses that the syntactic place is established not only by a space in the sentencing architecture but also for enunciative aspects which are mobilized to configure it as a place capable of offering referential progression to the event put into play by the saying. Specifically, the projection analysis of the place of the object performed by the verb, which is not necessarily explicit, demonstrates that the place of the object is marked as a route to the senses in escape (ORLANDI, 2012). It is verified that the explicit object absence does not disregard a virtual occupation by nominal formations, which materialize historically outlined regularities, and we propose the concept of exchange between nominal formations, assuming that the flow of senses can also be stimulated by the occupation of two (or more) different nominal formations in the same place of object.

Keywords: Semantics of enunciation. Senses in escape. Verbal object. 


\section{Introdução}

Dautada nos estudos desenvolvidos pela Semântica da Enunciação, a presente pesquisa propõe uma análise linguística para além dos aspectos previstos na gramática tradicional. Nesse sentido, partimos do pressuposto de que a relação entre a dimensão orgânica e a dimensão enunciativa da língua é constitutiva do fato gramatical.

Alicerçados na perspectiva de que as unidades gramaticais estabelecem relações semânticas entre si, voltamos nosso olhar para um lugar sintático que se manifesta na arquitetura das sentenças da Língua Portuguesa: o lugar sintático de objeto verbal. Assumimos, portanto, o pressuposto de que o lugar sintático de objeto é o lugar disponível para abrigar o novo, configurando-se como aquele que é propenso ao avanço textual, ainda que esse lugar não esteja organicamente ocupado. Desse modo, o recorte dessa pesquisa se dá em torno das regularidades demarcadas pelas condições formais da organicidade da língua - associadas a um domínio de sentido advindo de uma memória de dizeres - capazes de agregar ao lugar sintático de objeto referentes que o tornam a força motriz da progressão referencial. Além disso, pretendemos demonstrar em que medida esse lugar sentencial se marca como rota para a fuga de sentidos (ORLANDI, 2012) em determinados acontecimentos enunciativos. Dito de outra maneira, nossa intenção é demonstrar a produtividade do lugar sintático de objeto na manifestação dos sentidos em fuga.

O caminho metodológico que adotaremos nos levará a realizar um aprofundamento no que tange à posição teórica aqui assumida, cuja pretensão é aproximar aspectos orgânicos e enunciativos, visando ao estudo sintático-semântico do lugar sintático de objeto verbal. Em seguida, realizaremos um procedimento de análise tendo por base as postulações teóricas apresentadas e o corpus organizado em torno de textos coletados em mídias diversas, seja no formato impresso ou digital.

\section{Fundamentação teórica}

Com base em Dias (2007) e sob o viés da semântica da enunciação, assumimos que o funcionamento linguístico não se estabelece unicamente na dimensão das formas linguísticas, organicamente constituídas, mas também na dimensão simbólica. Nas palavras de Dias (2007, p. 193), "temos, de um lado, formações simbólicas não projetadas nas unidades e nas formas articuladas; de outro, formas articuladas que projetam formações simbólicas dispersas".

Tendo em vista, portanto, uma sintaxe de base semântica, trabalharemos com o conceito de enunciação como acontecimento histórico relativo à produção do enunciado, conforme Ducrot (1987), e essa formulação guardará relações com aquela proposta por Guimarães (2002, p.11) para quem a enunciação é "acontecimento de linguagem, que se faz pelo funcionamento da língua”. Em suma, para esses autores, apesar das particularidades dos estudos de cada um, a enunciação se constitui de um acontecimento enunciativo de natureza histórico-social.

Conforme essa vertente teórica, para analisar uma forma linguística, é essencial que ela faça parte de um acontecimento enunciativo, de um acontecimento do dizer, pelo fato de que a língua possibilita (ou não) dizer diante de determinadas regularidades. Guimarães (2007, p. 96) sustenta que "uma língua adquire sua identidade na relação entre a dimensão do enunciável e a dimensão da materialidade morfossintática, e é concebida como um sistema de regularidades". O autor acrescenta, ainda, que "o sentido de um enunciado é sua relação de integração ao texto em que está" (GUIMARÃES, 2018, p.42). Posto 
dessa maneira, e levando em conta a natureza histórico-social do acontecimento,

não se pode prescindir das regularidades históricas que constituem organicamente a língua, entretanto, a língua não é capaz de significar apenas a partir de seus elementos estruturais. Somente quando as regras linguísticas ganham acontecimento a língua adquire status de dizer (DALMASCHIO, 2013, p. 60).

A enunciação se dá, portanto, no cruzamento de uma memória com uma atualidade. Vale ressaltar que, na perspectiva em que esse trabalho se situa, a temporalidade não é compreendida como uma relação cronológica pontuada com exatidão no tempo. "A diferença que constitui a especificidade do acontecimento é uma temporalidade de sentidos: um passado, um presente e um futuro. Nesta medida o acontecimento não está no tempo, o acontecimento constitui sua temporalidade" (GUIMARÃES, 2018, p. 38). Assim, significar passa a ser uma demanda presentificada pelo ato de enunciar.

\subsection{0 referencial histórico e a pertinência enunciativa}

Pretendemos, nesta subseção, apresentar as concepções de pertinência enunciativa e de referencial histórico, assumidas neste trabalho.

Nossa filiação teórica postula que a memória exige regularizações presentes na língua, uma vez que se efetiva no interior de um referencial historicamente delineado. Para Dias (2013, p. 230), tudo

aquilo que é enunciável só é apreendido como tal em caso de unidades que se articulam de maneira a construir formulações socialmente pertinentes. Por sua vez, a articulação de unidades só cumpre o seu papel de apreender o enunciável se ela se assenta em formas regulares, combinadas segundo padrões relativamente estáveis.
Em vista disso, o enunciado ganha pertinência somente em função de uma instância de anterioridade da memória enunciativa que o sustenta. Dias (2009, p. 10) afirma que

para que as formas linguísticas possam dar suporte à significação, elas devem confrontar-se com a memória discursiva e o presente do acontecimento. Nessa direção, a memória da língua comporta uma latência, uma condição para o confronto entre a instância do dizível histórico e a instância de um presente. Nos termos de Guimarães (1996, p.32), por ser latente, a memória da língua "pode ser sempre outra coisa, para isso bastando que outras enunciações a façam derivar, mesmo que imperceptivelmente". Desse modo, uma forma na língua não é nem soma de seus diversos passados, nem deriva de um étimo, nem algo em si: senão uma latência à espera do acontecimento enunciativo, onde o presente e o interdiscurso a fazem significar.

Dessa forma, o acontecimento demanda o que Dias (2015) nomeia como pertinência enunciativa. Dito de outra forma, pelo fato de não haver significado antes de se enunciar, os efeitos de sentido se estabelecem somente a partir do instante em que há a presentificação da virtualidade que está no memorável, em observação a uma demanda de pertinência enunciativa. Logo, "o enunciado é um acontecimento na medida em que um campo de virtualidade, balizado sócio historicamente, entra em um espaço de enunciação, balizado por um referencial, que também se constitui na relação entre linguagem e sociedade" (DIAS, 2015, p. 245).

A ideia de referencial baseia-se na perspectiva de domínio referencial estabelecido por Foucault.

[...] Um "referencial" que não é constituído de "coisas", de "fatos", de "realidades", ou de "seres", mas de leis de possibilidade, de regras de existência para os objetos que aí se encontram nomeados, designados ou descritos, para as relações que aí se encontram afirmadas ou negadas. 0 referencial do enunciado forma o lugar, a condição, o campo de emergência, 
a instância de diferenciação dos indivíduos ou dos objetos, dos estados de coisas e das relações que são postas em jogo pelo próprio enunciado; define as possibilidades de aparecimento e de delimitação do que dá à frase seu sentido, à proposição seu valor de verdade. É esse conjunto que caracteriza o nível enunciativo da formulação, por oposição ao seu nível gramatical e seu nível lógico (FOUCAULT, 1986, p. 104).

A construção do referencial é essencial, portanto, para o estabelecimento de um conjunto de possibilidades de significação da realidade por meio do dizer.

\subsection{A formação nominal e o lugar sintático de objeto}

O estudo do conceito de formação nominal de Dias (2011, p. 275) também se faz pertinente nesse trabalho. Para o autor, a formação nominal (doravante FN) "abriga uma articulação em formas regulares da nossa língua”. Assim, a formação nominal

se constitui em centro de articulação temática. Na medida em que constituímos um tema, ou um foco de interesse na enunciação, estamos trazendo a memória de sentidos que se agregam aos nomes. As determinações contraídas pelos nomes, constituindo um grupo ou sintagma nominal, apresentam as condições de recebimento dos traços de atualidade advindos da construção temática na sua relação com o mundo contemporâneo [...] A constituição desse centro de referência pode ser captado pela língua em formato concêntrico, tendo um substantivo na nucleação, de forma a encapsular um conceito historicamente constituído [...] (DIAS, 2011, p. 275).

Sob a perspectiva enunciativa, enquanto unidade linguística, a FN se constitui como potencial temático. Em vista disso, essa unidade abarca palavras ou expressões que carregam em si referenciais de significação historicamente relevantes. Contudo, em oposição ao que as gramáticas tradicionais postulam, no que tange ao nome - e, por conseguinte, ao sintagma nominal que se aproxima do conceito de FN -, como sendo uma classe de palavras "[...] com que designamos ou nomeamos os seres em geral" (CUNHA, 1985, p. 171); a Semântica da Enunciação concebe a FN como um domínio de referências no campo da enunciação, ou seja, por assumir movimentos de sentido, seu conceito é mais abrangente em relação àquele que define sintagma nominal. A formação nominal, que remete à virtualidade da língua, representa o acontecimento do nome, ou seja, por ser um critério de acepção sobretudo enunciativo, "o objeto temático da fala" (AMORIM; DIAS, 1999) se aplica não somente às palavras, mas também a sentenças inteiras. A fim de elucidar essa perspectiva, Amorim e Dias (1999) elaboraram a seguinte estrutura:

Pedro falou do (s)

Pedro falou da (s)

Pedro escreveu sobre a (s)

Pedro escreveu sobre o $(\mathrm{s})$

Com essas estruturas, podemos dizer que:

(a) Pedro falou do amor

(b) Pedro falou do pênalti não marcado

(c) Pedro escreveu sobre a inexistência de leito nos hospitais

(d) Pedro falou da ausência de seu pai

(e) Pedro escreveu sobre a falta de verbas para a saúde

(f) Pedro falou da negação do visto de seu passaporte

Segundo o nosso estudo, o termo que preencher esse espaço em branco seria o objeto temático da fala (AMORIM; DIAS, 1999, p. 242).

O lugar de objeto se constitui, assim como outros lugares sintáticos, em um domínio linguístico que permite a produção de sentido pela língua. Conforme Dias (2013, p. 236),

os lugares sintáticos permitem o contato entre uma memória de ditos e atualidade do dizer. [...] Enquanto unidades formais, os lugares sintáticos qualificam-se na medida em que funcionam como portos de passagem em rotas de circulação de sentidos, de discursos para o enunciado, e desse para os espaços futuros da discursividade, que por sua vez serão bases para novos enunciados. 
Nessa direção, defendemos a tese de que o lugar sintático em causa nesse trabalho é constituído não apenas por um espaço na arquitetura da sentença, mas também por aspectos enunciativos que se mobilizam para configurá-lo como um lugar capaz de oferecer progressão referencial ao acontecimento posto em cena pelo dizer.

De maneira específica, a análise da projeção do lugar de objeto realizada pelo verbo, que não obrigatoriamente se materializará linguisticamente nos enunciados, objetiva demonstrar que esse lugar é profícuo para aquilo que Orlandi (2012) nomeia de fuga dos sentidos.

\subsection{Sentidos em fuga}

Para Orlandi (1995), os sentidos se produzem em uma tensão entre a paráfrase e a polissemia. Em outros termos, o conflito entre o mesmo e o diferente é a base para a constituição dos sentidos, uma vez que a produção de novas significações está, inevitavelmente, atrelada a significações anteriores. Por esse motivo, como dito anteriormente, a linguagem está sempre no nível da virtualidade, sendo, portanto, atualizada no ato de enunciação, devido a regularidades organizadas na historicidade da língua.

Por historicidade, Orlandi (2012, p.13) entende a maneira pela qual "os sentidos se constituem na relação da linguagem com a exterioridade [constitutiva]". Dessa forma, os enunciados são ressonâncias de diversas histórias de dizeres. Essa retomada de enunciados historicamente regularizados, consoante a autora, é capaz de produzir movimentos de sentidos.

Por essa razão, retomando Pêcheux (1990), Orlandi (2012, p. 13) afirma que,

ao produzir um deslizamento, uma mexida na repetição, provoco um efeito sobre o sentido que estou produzindo e sobre aquele de que ele desliza. Se $a \rightarrow b$, então, em retorno, o deslizamento para $b$ provoca um efeito também sobre $a$. [...]. É, pois, com a historicidade que estaremos lidando, entre outros, que não é, entretanto, deriva mas sentidos em fuga: repetição, imitação e polissemia. Algo é apresentando sob várias formas, ou inscrito em várias formações (discursivas). Re-formulações.

Em suma, "é preciso que fuga não seja entendida como o que foge, mas o que ocorre, desliza, vai, ressoa, ecoa, arrebanha sentidos em movimento, em outro lugar. Sem deixar de ter sua relação com o silêncio, com o silenciamento" (ORLANDI, 2012, p. 19).

Em complemento aos pressupostos apresentados pela autora, e voltando a reflexão para o fato linguístico abordado nesta pesquisa, é possível afirmar que a projeção do lugar sintático de objeto não demanda, necessariamente, a explicitude de uma materialização linguística, por meio de uma formação nominal, em sua configuração. Isso corrobora Orlandi (1995, p. 24) de que "para dizer é preciso não-dizer". Essa não ocupação, de natureza orgânica, do enunciado é denominada por Dalmaschio (2008) como "silêncio sintático", que, nas palavras da pesquisadora, "não se constitui, em nosso fundamento teórico, como a falta linguística. Isso nos leva a afirmar que o silêncio sintático não se constitui como nada" (DALMASCHIO, 2013, p. 131).

o silêncio sintático seria, portanto, um lugar na organicidade da sentença, aqui especificamente o lugar sintático de objeto, que permite a possibilidade do movimento dos dizeres. Movimento esse que se constitui sócio historicamente a partir de uma tensão entre memória e atualidade (DALMASCHIO, 2013, p. 116).

Parafraseando Orlandi (2012), para que o sentido "deslize" é preciso silenciar. No entanto, é necessário certificar-se de que determinadas enunciações estejam incorporadas à rede de memórias - que se constituem enquanto redes de possibilidades de sentido, que permitem o deslocamento desses sentidos -, para que sejam aceitas linguisticamente. 
Sentidos em fuga não são só sentidos que deslizam, e a não coincidência é fato da metáfora: uma palavra por outra, transferência. Não é, tampouco, uma questão de heterogeneidade. [...] Explosão que desestabiliza e produz movimento desordenado (ORLANDI, 2012, p. 25).

A fim de elucidar essa noção, Orlandi (2012, p.22-23) usou como exemplo um enunciado, cuja cena enunciativa é o Senado. Esse trecho é, portanto, "uma resposta de Dilma a uma acusação de José Agrippino que cita as palavras de Dilma para trazer a questão sobre a mentira e o regime de exceção do regime da ditadura militar no Brasil".

Qualquer pessoa que ousar dizer a verdade para interrogadores entrega pessoas para serem mortas. Eu me orgulho de ter mentido. Porque mentir, na tortura, não é fácil. [...]. Na democracia se fala a verdade. Durante a tortura, quem tem coragem, dignidade, fala mentira. [...] (Hoje) Não estamos em um diálogo entre meu pescoço e a forca. [...] Não há verdade, não há espaço para a verdade...isso que é morte...porque não há espaço para a verdade, porque não há espaço para a vida (na tortura) (ORLANDI, 2012, p. 22-23, grifo da autora)

O enunciado em negrito provoca, portanto, uma quebra de referenciais historicamente estabelecidos - a mentira não é motivo de orgulho -, para que, através da fuga de sentidos, novos referenciais, novas possibilidades de significados se constituam na enunciação - em certos casos a mentira é motivo de orgulho.

\section{Sentidos em fuga: da polissemia e do silêncio ao intercâmbio entre formações nominais na constituição de sentidos}

Para efeito de análise, a presente seção será dividida em três eixos. Os dois primeiros discutirão a manifestação dos sentidos em fuga por meio da polissemia (exemplos (1) e (2)) e do silêncio (exemplos de (3) a (7)), propostos pela professora e pesquisadora Eni Orlandi (2012); e o terceiro apresentará uma contribuição desta pesquisa, em relação a uma nova maneira de percebermos a materialização da fuga de sentido no lugar de objeto verbal (exemplos de (8) a (11)).

\subsection{Efeitos da polissemia no processo de constituição dos sentidos}

O foco desta primeira parte da análise pauta-se no conceito de polissemia de Orlandi (1995, p.12). Para a autora, a polissemia se estabelece através dos "diferentes movimentos de sentidos no mesmo objeto simbólico". Desse modo, em um primeiro momento, serão analisados os efeitos da fuga de sentidos no lugar de objeto por meio da polissemia.

O ponto de partida se dará em torno da manchete presente na Figura 1, publicada no Jornal da Tarde de dezembro de 1994, em decorrência da morte de Tom Jobim.

Figura 1 - Manchete do Jornal da Tarde ${ }^{1}$

(1)

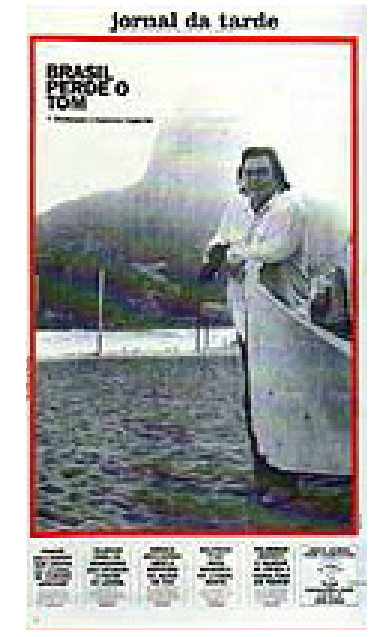

Fonte: Jornal da Tarde de São Paulo, 9 de dezembro de 1994.

Disponível em: http://www.pontodevista.jor.br/blog/galeria.php. Acesso em: 9 set. 2017. 
Ao investigar o enunciado "Brasil perde o Tom", é possível tecer um conjunto de possibilidades de sentidos delineado pelo objeto simbólico "Tom Jobim". Assim sendo, o substantivo "Tom" ocupa o lugar sintático de objeto projetado pelo verbo "perder", instaurando um campo referencial que, por sua vez, gera efeitos de sentidos para esse enunciado. Contudo, essa ocupação permite a produção de, pelo menos, dois sentidos diferenciados. Em outros termos, há mais de um efeito de sentido para o mesmo objeto simbólico, pelo fato de que a FN "Tom" carrega, em si, referenciais historicamente relevantes. O primeiro viés semântico faz com que a FN "o Tom" se refira à perda do próprio músico Tom Jobim, que aparece em destaque na imagem utilizada pelo jornal, junto à manchete que anuncia sua morte. Já o segundo, faz alusão à perda da melodia, do ritmo representados pelas composições do cantor. Em virtude disso, a segunda análise adquire pertinência, somente, assentada no referencial histórico de que Tom Jobim era um compositor e cantor brasileiro prestigiado.

Outro enunciado que exemplifica a polissemia se faz presente na Campanha Estadual de Enfrentamento à Violência, Abuso e Exploração Sexual de Crianças e Adolescentes, exemplo (2), do Governo de Minas Gerais, exposto na Figura 2.

No segundo exemplo, o substantivo "pena" ocupa o lugar sintático projetado pelo verbo "dar". A FN "pena" agrega contornos de atualidade que permitem a criação de novas cenas enunciativas que se constituem na memória.

Em um primeiro momento, essa FN inscreve-se no referencial histórico da emoção, dos sentimentos de tristeza e melancolia (dá tristeza, dá melancolia) - ao se observar, também, a imagem de uma menina amedrontada -, posto que o ato de explorar e abusar sexualmente de crianças e adolescentes causa consternação. Entretanto, outro recorte de sentido se configura ao se tomar a cena enunciativa como um todo, dado que o acionamento de outro enunciado, presente na propaganda, "Pena de 1 a 12 anos de prisão", sugere que a FN "dá pena” investe-se referencialmente da ideia de punição, problema (dá punição, dá problema) àqueles que cometerem o crime de exploração sexual infantil.

Figura 2 - Propaganda do Governo do Estado de Minas Gerais ${ }^{2}$

(2)

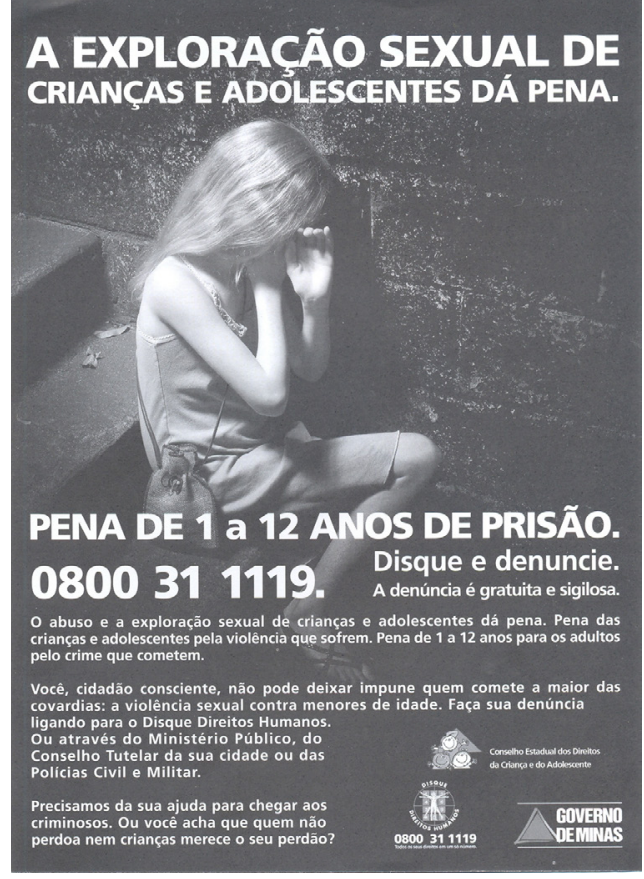

Fonte: Imagem retirada do Google.

Esses exemplos ilustram, portanto, o efeito da polissemia, já que, conforme Orlandi (1995), o conflito entre o mesmo e o diferente constitui a base de novos sentidos.

${ }_{2}$ Disponível em: https://campanhaproteja.wordpress.com/material/. Acesso em: 12 set. 2017. 


\subsection{Efeitos do silêncio no processo de constituição dos sentidos}

O segundo foco de análise pauta-se no conceito de silêncio de Orlandi, segundo a qual é "um dos eixos responsáveis pela fluência da interpretação. [...] Ele é o ponto de apoio do giro interpretativo" (ORLANDI, 1995, p. 164). Em outros termos, entendemos que movimentos de sentidos se instalam no interior dos enunciados também por meio do silêncio sintático (DALMASCHIO, 2008).

É importante destacar que ao apresentarmos a noção de silêncio sintático

tentamos redimensionar a noção de transitividade verbal proposta pelas gramáticas tradicionais, e mesmo por algumas de base não-tradicional, que explicam a presença de um objeto em um enunciado pela determinação de um verbo transitivo e, consequentemente, a ausência desse complemento por força da presença de um verbo intransitivo (DALMASCHIO, 2008, p. 43).

Entendemos que a classificação dos verbos em transitivos e intransitivos não é suficiente para abarcar toda a complexidade que esse fenômeno adquire no processo de funcionamento da linguagem. Defendemos que o papel assumido por todos os verbos, no enunciado, é o de projetar o lugar de objeto, cuja ocupação passa a ser regulada pelas condições enunciativas, não estando o objeto, portanto, circunscrito a uma necessidade de complementação do sentido desse verbo ${ }^{3}$.

A primeira evidência da fuga de sentidos por meio do silêncio será investigada em um anúncio publicitário, retirado do vídeo do medicamento "Gelol", utilizado com o intuito de combater as dores musculares e lesões causadas por quedas 4 .

3 Para uma análise mais aprofundada sobre esse posicionamento teórico, ver Dalmaschio $(2008 ; 2013)$. 4 Disponível em: https://www.youtube.com/watch?v=5xblBENQlaI. Acesso em: 18 set. 2017.
(3) "Caiu? Bateu? Machucou? Passa Gelol, que passa."

O exemplo (3) "Caiu? Bateu? Machucou? Passa Gelol, que passa" revela que os lugares sintáticos de objeto projetados pelos verbos "caiu", "bateu" e "machucou" não apresentam ocupação orgânica. Entretanto, esses verbos expressam potencial de projeção desse lugar sintático. Por que, então, a ausência linguística de um elemento que preencha esses espaços? Parece que uma resposta a essa questão está intimamente ligada às condições enunciativas que regulam a constituição desse acontecimento. Não ocupar o lugar de objeto nessa propaganda significa ampliar o domínio referencial desse lugar. Dessa forma, sintagmas nominais como "o pé", "a cabeça", "o ombro", e tantos outros podem se configurar como ocorrências passíveis de ocupar o lugar de objeto projetado pelos verbos "bateu" e "machucou". Nesse sentido, percebemos que esse anúncio ganha em eficiência enunciativa, no instante em que se organiza em torno de um modo de enunciação genérico.

É interessante frisarmos que o caráter generalizador de (3) é tão alto que acaba transformando o enunciado "Caiu? Bateu? Machucou?" em textofonte de outras enunciações, como pode ser percebido no exemplo (4), que corresponde a uma passagem da Homilia de Frei Denilson de Freitas da Silva $(2013)^{5}$ :

(4) [...] A fé cristã deve iluminar a vida em todas as suas dimensões - por isso dizemos que o testemunho, o exemplo de vida são importantes; a fé em Cristo me faz entender que eu devo ser no meio dos outros, nos diversos lugares, na sociedade... um outro Cristo na terra. Mas existem os chamados "cristãos Gelol". Se lembram da propaganda do Gelol: caiu, bateu, machucou... passa Gelol que passa (risos). Equivocadamente, esse 'povo Gelol' vê a fé como algo que anestesia (ilusoriamente)

5 Disponível em: http://www.clic101.com.br/ver/377/Pela-fe-Pedro-Tiago-e-Joao-\%E2\%80\%9Catracaramas-barcas-deixaram-tudo-e-seguiram-a-Jesus\%E2\%80\%9D-(Lc-511). Acesso em: 20 set. 2017. 
suas vidas. Qual é o desdobramento disso? Diante dos problemas, das dificuldades, das intempéries da vida humana... reza que passa! Isso não é fé cristã. Ela não resolve as coisas de forma mágica. A fé em Cristo ilumina a vida para que as decisões corretas sejam tomadas e a fortalece para que, mesmo em meio às turbulências (que são as trevas) continuemos a caminhar com a chama da fé. Então, é preciso caminhar, perseverar, seguir a Cristo.

O discurso religioso trazido pelo exemplo (4) trata da questão da busca pela fé somente em situações de grande desespero, como uma forma de amenizar os problemas diários. No entanto, a expressividade do enunciado "Caiu? Bateu? Machucou? [...] Reza que passa!" se dá no momento em que o pregador adapta a expressão original "Passa Gelol, que passa", à nova cena enunciativa, ou seja, a um ambiente religioso, resultando em "Reza que passa!". Ou seja, o referencial histórico que sustenta (4) não mais diz respeito a "machucar o corpo", como em (3), mas em "machucar a alma". As novas possibilidades de ocupação dos lugares sintáticos de objeto, projetados pelos verbos "bater" e "machucar", tornam-se legítimos devido à ampliação do domínio referencial, proporcionado pelo silêncio desse lugar. Logo, possíveis formações nominais que ocupariam o lugar de objeto verbal de "bateu" e "machucou", de acordo com a cena enunciativa do enunciado em questão, seriam: "Bateu a alma?" ou, ainda, "Machucou o coração?". Quanto ao verbo "cair", embora entendamos que também seja revestido da capacidade de projeção do lugar sintático de objeto, a memória de regularidades dos trajetos enunciativos por ele percorridos oferece pertinência para que a predicação de que participa oriente para ele próprio a direção da predicação, configurando o que Dias (2006) nomeia "predicação centrada".

Nessa direção, percebemos, nos enunciados (3) e (4), que o silenciamento coloca em cena o que temos nos esforçado para ilustrar como fuga dos sentidos. Ou seja, dois referenciais distintos são acionados, em interface, para que o enunciado "Caiu? Bateu? Machucou?" se configure como pertinente e signifique.

Outro indício da fuga de sentidos por meio do silêncio se revela no exemplo (5), presente na Figura $3^{6}$.

Figura 3 - Frase utilizada em status de rede social - 1

(5)

\section{Ela só dá por prazer, inclusive, a volta por cima.}

Allê Barbosa

@allebarbosza

Fonte: Imagem retirada do Google.

Ao contrário dos dois exemplos anteriores, (3) e (4), em que o silêncio é mantido, não havendo, portanto, materializações subsequentes, o exemplo (5) apresenta o lugar de objeto, projetado pelo verbo "dar", silenciado no primeiro enunciado. No entanto, a materialização ocorre logo em seguida, com a FN "a volta por cima", como se o verbo "dar" e o pronome "ela" estivessem se repetindo, de maneira elíptica, criando, dessa maneira, um novo enunciado. Expliquemos melhor. Em "Ela só dá por prazer", há um direcionamento argumentativo, fixado pela regularidade de sentido constituída pela articulação histórico-social das formas linguísticas que fazem parte da estruturação desse enunciado, que orienta a ocupação

${ }^{6}$ Disponível em: http://www.thepicta.com/user/allebarbosza/519812781. Acesso em: 24 set. 2017. 
do lugar sintático de objeto do verbo "dar" com FNs assentadas em um referencial voltado à sexualidade. Todavia, a demanda de pertinência desse texto ancora-se em um novo referencial histórico e esse referencial marca-se pela FN "a volta por cima" que, ao lado de todas as outras FNs virtualmente capazes de ocuparem o lugar sintático em questão, amplia o domínio referencial desse lugar, demonstrando que o sentido se movimenta em silêncio, se coloca em rota de circulação, de fuga.

Semelhante ao exemplo (5), em (6), há a quebra do silêncio e a materialização do lugar sintático projetado pela forma verbal "fazer", manifestando, também, a fuga de sentidos ${ }^{7}$.

Figura 4 - Frase utilizada em status de rede social - 2

(6)

$$
\begin{aligned}
& \text { Tue eu faço com a saudade? } \\
& \text { Tem dia que faço besteira. } \\
& \text { Tem dia que faço caipirinha. } \\
& \text { Depende muito.. } \\
& \text { Hoje, fiz brigadeiro. }
\end{aligned}
$$

Fonte: Imagem retirada do Google.

Nesse exemplo, assim como no anterior, há a criação de uma pertinência de outra ordem, já que não está na ordem do regular dizer que é possível fazer brigadeiro com a saudade, por exemplo. Ao se materializar o dizer que, a princípio, é silenciado, origina-se a expressividade do texto. Desse modo, o verbo "fazer", que participa regularmente de enunciações cuja

\footnotetext{
7 Disponível em: http://jhulira.blogspot.com.br/2012/07/vontade.html. Acesso em: 24 set. 2017.
}

predicação não se marca com a presença de um objeto, em (6) compõem novos enunciados com esse lugar sintático ocupado, de modo a permitir que os sentidos se mobilizem em outras direções que só são possíveis em função do silêncio marcado na interrogação. Assim, o referencial da tristeza sofre uma desestabilização e novos referenciais passam a se configurar. Afinal, fazer "brigadeiro" com a saudade manifesta uma tentativa de alegrar-se, em meio à dor. Nessa direção, o silêncio possibilita a fuga e "sentidos em fuga não são só sentidos que deslizam...É desmanche. Explosão que desestabiliza e produz movimento desordenado" (ORLANDI, 2012, p. 25)

Nessa direção, tanto no exemplo (5), quanto no exemplo (6), há um lugar de objeto silenciado, cujo domínio referencial das FNs passíveis de ocupar esse lugar já está regularizado sócio-historicamente, seja em relação ao verbo "dar" ou ao verbo "fazer". Contudo, em ambos os casos, há uma quebra de perspectiva ao se recortar as novas FNs que ocupam o espaço disponível para a progressão textual.

Outro exemplo que ilustra o efeito da fuga de sentidos possibilitada pelo silêncio sintático do lugar de objeto pode ser percebido em $(7)^{8}$.

\section{(7) Galera!}

Tenho um amigo que recentemente comprou um iPhone 7, mas o filho dele quebrou a tela, então ele está doando. Se alguém quiser, avisa no particular. 0 menino tem 8 anos, é magro, come pouco, não dá muito trabalho.

Constatamos que se trata de um texto que pertence a um gênero humorístico, logo, sua construção discursiva se estabelece tendo em vista essa finalidade. Percebemos que a locução verbal "está doando" projeta um lugar de objeto que não é ocupado e essa não ocupação permite que esse enunciado seja inserido em dois referenciais distintos. A FN que orienta

${ }^{8}$ Disponível em: https://www.facebook.com/groups/facebriquefw/1035071103248173/. Acesso em: 24 set. 2017. 
o domínio de sentidos funcionando como objeto passível de ocupação do lugar projetado por essa forma verbal seria "um iPhone 7". Todavia, para a constituição do humor, foi agregado ao texto o enunciado "O menino tem 8 anos, é magro, come pouco, não dá muito trabalho", que funciona como desencadeador de uma nova ocupação para o lugar de objeto: agora o alvo da doação passa a ser "o filho". Assim, a FN "um iPhone 7" habita um lugar de memória que dá ao objeto um caráter de institucionalização. Ao se quebrar essa institucionalização, mas trabalhando no campo das possibilidades (com a agregação da FN “o filho"), cria-se, então, o humor. Nesse sentido, Pêcheux (1998) afirma que faz parte da sintaxe tanto o jogo das regras quanto o jogo sobre as regras, no mesmo lugar onde elas se constituem.

Nesta perspectiva, a sintaxe seria, ao contrário, o que toca de mais perto no próprio da língua enquanto ordem simbólica, com a condição de dissimetrizar o corpo das regras sintáticas, construindo aí os efeitos discursivos que o atravessam, os jogos internos destes 'espelhamentos' léxico-sintáticos através dos quais toda construção sintática é capaz de deixar aparecer uma outra, no momento em que uma palavra desliza sobre outra palavra (PÊCHEUX, 1998, p. 28)

É importante frisar que não se espera em (7) que uma ou outra FN seja considerada mais ou menos "adequada" para a ocupação do lugar de objeto de "está doando". Afinal, o silêncio sintático corresponde em nossa perspectiva a um horizonte e não a uma falta e, no caso do texto em análise, silenciar esse lugar é condição fundamental para a produção do humor.

\subsection{Intercâmbio entre formações nominais no processo de \\ constituição dos sentidos}

Com o intuito de agregar um novo viés ao trabalho de Orlandi (2012), a análise deste tópico buscará pensar o efeito da fuga de sentido no lugar de objeto não por meio da polissemia, tampouco pelo silêncio, mas pelo
Intercâmbio entre FNs que podem ocupar esse espaço. Um exemplo que ilustra essa nova perspectiva pode ser observado em:

Figura 5 - Postagem do Facebook ${ }^{9}$

(8)
poder

\section{FHC recebeu vantagens indovidas em} eleições, diz dono da Odebrecht

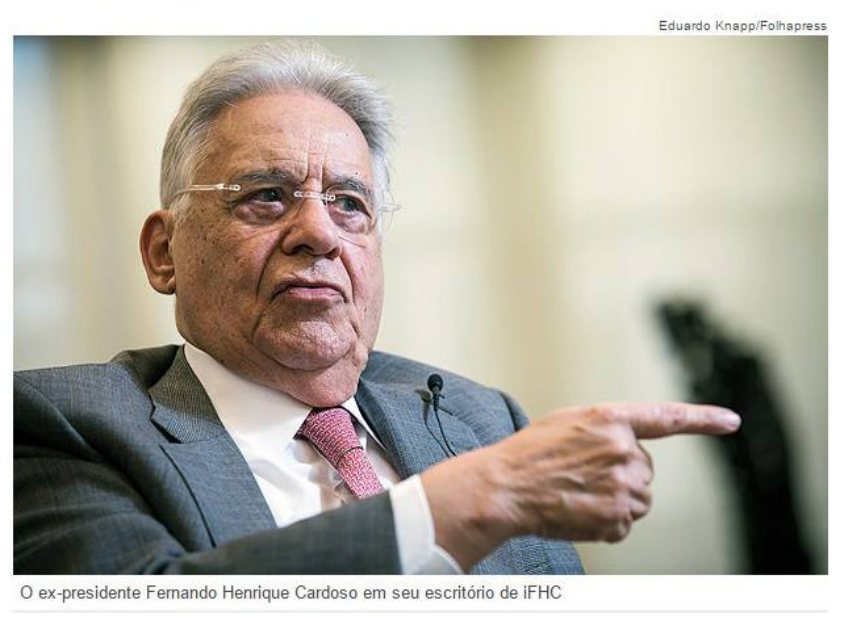

Fonte: Página do Facebook - Caneta Desmanipuladora.

O enunciado, ao ter seu sentido inicial modificado, por meio da rasura em vermelho, demonstra como FNs distintas podem influenciar na orientação argumentativa que o texto pretende trazer. Como se vê, duas formações nominais diferentes - "vantagens indevidas" e "propinas" puderam ocupar o mesmo lugar de objeto. Entretanto, o uso de uma ou

${ }_{9}$ Disponível em: https://www.facebook.com/canetadesmanipuladora/. Acesso em: 24 set. 2017. 
de outra recorta diferentes possibilidades de sentido. Afinal, "vantagens indevidas" suaviza o referencial de corrupção que "propina" acentua. O que reafirma a ideia de que "o sujeito não é exato. Constituídos pela metáfora, sujeitos e sentidos não coincidem em si, não coincidem entre si, se movem, se deslocam, fogem..." (ORLANDI, 2012, p. 27).

Continuemos esse ponto de nossa análise observando o que ocorre nos enunciados (09), (10) e (11).

\section{(09) A união faz a força sempre ${ }^{10}$}

A vida coloca diante de nós vários obstáculos diariamente. Estes obstáculos muitas vezes desviam o nosso olhar daquilo que realmente é importante para nós, mas se olhamos em frente e continuamos vendo ao longe o nosso sonho, a meta que queremos alcançar, é porque esse obstáculo não é grande o suficiente para nos fazer desistir!

Precisamos manter o foco naquilo que queremos conquistar, precisamos manter o foco no que é bom, no que nos fortalece, no que nos estimula a continuar caminhando, mesmo quando achamos que já não somos capazes. Para quem sonha, desistir nunca é uma opção.

E o trabalho em equipe só nos faz sentir mais fortes, pois quando achamos que já não podemos continuar, os nossos colegas nos ajudam a olhar para a frente, e nos mostram novamente o caminho que devemos seguir. Com uma boa equipe nunca se fica perdido no deserto, é a união que faz força e que faz de nós mais fortes em nossas conquistas!

O nosso maior incentivo é e sempre será a satisfação que sentimos quando conseguimos ultrapassar todos os obstáculos para chegarmos onde queremos, com respeito, solidariedade e espírito de equipe!

\footnotetext{
${ }^{10}$ Disponível em: https://www.mundodasmensagens.com/mensagem/a-uniao-faz-a-forca-sempre.html. Acesso em: 25 set. 2017

Figura 6 - Meme Tiririca ${ }^{11}$

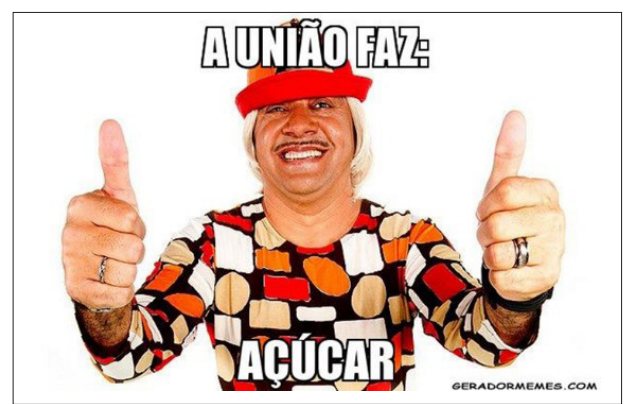

Fonte: Imagem retirada do Google.

\section{Funk White}

Mamonas Assassinas ${ }^{12}$

De repente a gente se une

Todo mundo junto

Sabendo que a união faz o açúcar

E também a força

Porque a gente precisa é muita coisa

Pra subir nessa vida meu deus.

O efeito de fuga de sentidos se dá, nos exemplos anteriores, devido ao intercâmbio de formações nominais que ocupam o lugar sintático de objeto projetado pelo verbo "fazer" no enunciado "A união faz". Em (09), o lugar de objeto é ocupado pela FN "a força". A regularidade de uso transforma esse enunciado - "A união faz a força" - em um provérbio, capaz de ser mobilizado em textos motivacionais, como está materializado no exemplo em questão. Todavia, em (10), o mesmo enunciado ancora-se em outro referencial, o do humor, e é utilizado para brincar com uma marca de produtos alimentícios, ou seja, há um deslocamento do sentido proverbial, acionado

${ }^{11}$ Disponível em: http://geradormemes.com/meme/1a0vfd. Acesso em: 25 set. 2017.

${ }_{12}$ Disponível em: https://wwwletras mus.br/mamonas-assassinas/1846046/. Acesso em: 25 set. 2017. 
pelo intercâmbio entre as FNs que ocupam o lugar de objeto, que passa a figurar em outra cena enunciativa. Logo, o objeto adquire sua identidade semântica tendo em vista a demanda de pertinência presentificada pelo acontecimento em ato. Vale ressaltar que só podemos trabalhar a noção de deslocamento em função da repetição, do hábito. 0 enunciado (10) - "A união faz açúcar" - corresponde a uma reestruturação de (09) - "A união faz a força". Afinal, acreditamos que é "recorrendo ao já-dito que o sujeito resignifica. E se significa" (ORLANDI, 1995, p. 90). O que podemos perceber é que os diferentes percursos de sentido do verbo "fazer" são elementos que possibilitam a construção de domínios de referência também distintos para a ocupação do lugar de objeto. Trata-se de um intervalo entre uma memória de recorrências e uma atualidade de uso. Esse seria, então, o espaço do equívoco, espaço esse em que "os sentidos não se imobilizam... não perdem seu caráter errático: deslocamentos, equívocos e mudanças se produzem. E não param de produzir seus efeitos" (ORLANDI, 1995, p. 94).

A fuga de sentidos possibilitada pelo intercâmbio entre as FNs "a força" e "açúcar" pode ser percebida de forma mais evidente em (11) onde as duas passam a ocupar no mesmo texto os lugares de objeto projetados pelo verbo fazer - "Sabendo que a união faz o açúcar/E também a força". Tratase de um jogo de sentidos que pode ser considerado como uma relação de apontamento entre recortes de memória. Assim, os enunciados dialogam com o memorável e, ao realizar esse diálogo, se configuram em duas direções: a direção de retomar o já-dito e a direção de devolvê-lo diferente para uma virtualidade passível de nova atualização.

\section{Considerações finais}

Discutimos neste texto a produtividade do lugar sintático de objeto verbal sob a ótica da relação entre as configurações orgânicas da língua e suas projeções de acionamento enunciativo, uma vez que a enunciação é um acontecimento de natureza histórico-social.

Em um primeiro momento, procuramos analisar os efeitos da polissemia na constituição dos sentidos. Tomando os estudos de Orlandi (2012) acerca da polissemia, ilustramos a fuga de sentidos, especificamente no lugar de objeto verbal, em um mesmo objeto simbólico. A produção de dois sentidos distintos em um único objeto só foi possível devido à ampliação do domínio referencial que as FNs analisadas propiciam.

Em seguida, embasados nos estudos de Orlandi (1995), averiguamos a movimentação dos sentidos em enunciados cujos lugares de objeto verbal não estejam organicamente ocupados. Verificamos que a ausência de um objeto explícito não prescinde de uma ocupação virtual desse lugar por FNs que materializem regularidades historicamente delineadas. Em outros termos, o efeito de sentido provocado pelo silenciamento se ancora no memorável para se manifestar.

A fim de contribuir para os estudos acerca do funcionamento linguístico, propomos o conceito de "intercâmbio entre formações nominais". Assim, partimos do pressuposto de que o fluxo dos sentidos pode, também, ser estimulado pela ocupação de duas (ou mais) formações nominais diferentes no mesmo lugar de objeto. Em outras palavras, ao optarmos por empregar FNs distintas em um mesmo lugar, investimos na movimentação dos efeitos de sentidos.

Diante das discussões aqui apresentadas, vimos defendendo que o sentido que se manifesta em determinado enunciado deriva do efeito de enunciações anteriores atualizadas pela relação estabelecida entre os referenciais históricos e as demandas de pertinência que ancoram os acontecimentos enunciativos em ato. 


\section{Referências}

AMORIM, Karine Viana; DIAS, Luiz Francisco. Verbos no infinitivo na posição de substantivo: uma abordagem enunciativa. In: JORNADA DE ESTUDOS LINGUÍSTICOS DO GELNE, 17., 2000, Fortaleza. Anais [...]. Fortaleza: Universidade Federal do Ceará, 1999. v. 1, p. 241-244.

CUNHA, Celso; CINTRA, Lindley. Nova gramática do português contemporâneo. 2. ed. Rio de Janeiro: Nova Fronteira, 1985.

DALMASCHIO, Luciani. Enunciação e sintaxe: modos de enunciação genéricos na ocupação do lugar sintático de objeto. 2008. Dissertação (Mestrado em Linguística)

- Programa de Pós-Graduação em Estudos Linguísticos, Faculdade de Letras,

Universidade Federal de Minas Gerais, Belo Horizonte, 2008.

DALMASCHIO, Luciani. Predicação dirigida x predicação centrada: a (não)ocupação do lugar de objeto na perspectiva da semântica da enunciação. 2013. Tese (Doutorado em Linguística) - Programa de Pós-Graduação em Estudos Linguísticos, Faculdade de Letras, Universidade Federal de Minas Gerais, Belo Horizonte, 2013.

DIAS, Luiz Francisco. Enunciação e forma linguística. Revista de Estudos da Linguagem Belo Horizonte, v. 21, n. 1, p. 223-238, jan./jun. 2013. https://doi.org/10.17851/22372083.21.1.223-238

DIAS, Luiz Francisco. Enunciação e gramática: o papel das condições de emprego da língua. Letras, Santa Maria, n. 33, p. 51-67, jul./dez. 2006.

DIAS, Luiz Francisco. Enunciação e regularidade sintática. Cadernos de Estudos Linguísticos, Campinas, v. 51, n. 1, p. 7-30, jan./jun. 2009. https://doi.org/10.20396/cel. v51i1.8637217

DIAS, Luiz Francisco. Gramática e política de língua: institucionalização do linguístico e constituição de evidências linguísticas. In: ORLANDI, Eni Puccinelli (org.). Política linguística no Brasil. Campinas: Pontes Editores, 2007. p. 183-200.

DIAS, Luiz Francisco. Os sentidos da liberdade no mundo wiki. In: SCHONS, Carme Regina; CAZARIN, Ercília Ana (org.). Língua, escola e mídia: en(tre)laçando teorias, conceitos e metodologias. Passo Fundo: UPF Editora, 2011. p. 272-287.
DIAS, Luiz Francisco. Sentido e enunciação: a atualidade do conceito de acontecimento na semântica. Estudos da Lingua(gem), Vitória da Conquista, v. 13, n. 1, p. 229-248, jun. 2015 .

DUCROT, Oswald. Esboço de uma teoria polifônica da enunciação. In: DUCROT, Oswald. o dizer e o dito. Campinas: Pontes Editores, 1987.

FOUCAULT, Michel. A arqueologia do saber. Rio de Janeiro: Forense Universitária, 1986.

GUIMARÃES, Eduardo. Domínio semântico de determinação. In: GUIMARÃES, Eduardo; MOLLICA, Maria Cecília (org.). A palavra: forma e sentido. Campinas: Pontes Editores, 2007.

GUIMARÃES, Eduardo. Enunciação, língua, memória. Revista da ANPOLL, Florianópolis, n. 2, p. 27-33, 1996. https://doi.org/10.18309/anp.v1i2.238

GUIMARÃES, Eduardo. Semântica do acontecimento: um estudo enunciativo da designação. Campinas: Pontes Editores, 2002.

GUIMARÃES, Eduardo. Semântica: enunciação e sentido. Campinas: Pontes Editores, 2018.

ORLANDI, Eni Pulccinelli. As formas do silêncio: no movimento dos sentidos. 3. ed. Campinas: UNICAMP, 1995.

ORLANDI, Eni Pulccinelli. Sentidos em fuga: efeitos da polissemia e do silêncio. In: CARROZA, Guilherme; SANTOS, M. dos; SILVA, T. D. da (org.). Sujeito, sociedade, sentidos. Campinas: Pontes Editores, 2012

PÊCHEUX, Michel. Lecture et mémoire: projet de recherche. In: MALDIDIER, Denise. L'inquiétude du discours: textes de Michel Pêcheux. Paris: Éditions des Cendres, 1990 p. 285-293.

PÊCHEUX, Michel. Sobre a (des-)construção das teorias linguísticas. Línguas e Instrumentos Linguísticos, Campinas, n. 2, p. 7-31, jul./dez. 1998. 